\title{
The Trend of BIPA Research in the International Scope: A Bibliometric Analysis
}

\author{
Chafit Ulya $^{1}$, Muhammad Rohmadi ${ }^{2}$, Memet Sudaryanto ${ }^{3}$, Fateemah Chewoh ${ }^{4}$, \\ Aboyitungiye Jean Baptiste-Burundi ${ }^{5}$ \\ 1,2,3 Sebelas Maret University, Indonesia \\ ${ }^{4}$ Fatoni University \\ ${ }^{5}$ The University of Burundi \\ ${ }^{1}$ chafit@staff.uns.ac.id; ${ }^{2}$ mamad r76@staff.uns.ac.id; \\ 3memetsudaryanto@staff.uns.ac.id
}

\begin{abstract}
Bahasa Indonesia showed well improvement in the international world by increasing the number of countries which learned it. Various research and scientific publications have continuously been conducted to strengthen the existence of Bahasa Indonesia, including in the Scopus publication. This writing showed the mapping of scientific studies regarding BIPA topics in the Scopus website aiming to describe the trend of BIPA research based on (1) the quantity of documents from year to year, (2) the type of document: (3) the nationality of the author; (4) co-word and co-author. This research used the bibliometric analysis from the Scopus database by using the keyword Indonesian for foreign language, which were found 201 documents. Furthermore, data were analyzed using Microsoft Excel 2010 and VOSviewer. The results obtained from this study were: (1) the trend of BIPA research in the Scopus website has improved every year; (2) the document of publication was dominated by the journal articles; (3) BIPA research was still dominated by the authors from Indonesia; (4) the trends of the development of BIPA research based on co-word and co-author were divided into five clusters. By noticing this development, it was expected that the researchers who were interested in BIPA could explore and enrich the topics for the maintaining of BIPA existence in the international stage.
\end{abstract}

Keywords: BIPA, foreign language, international, bibliometric, vos viewer

\section{PENDAHULUAN}

Bahasa Indonesia menunjukkan perkembangan yang sangat baik di kancah internasional. Saat ini, setidaknya sudah ada 56 negara yang mengajarkan bahasa Indonesia, baik secara formal maupun nonformal [1]. Beberapa negara bahkan sudah menjadikan bahasa Indonesia sebagai bahasa kedua, seperti yang dilakukan oleh Pemerintah Daerah Ho Chi Minh City, Vietnam, sejak 2009 (Kompas.com). Selain itu, sudah banyak perguruan tinggi di negara-negara asing yang membuka jurusan Bahasa Indonesia, di antaranya Polandia, Thailand, Jerman, India, 
Ukraina, Rusia, Maroko, Uzbekistan, Belanda, dan sebagainya [2]. Perkembangan ini menunjukkan tren yang positif bagi bahasa Indonesia.

Oleh karenanya, berbagai kajian, penelitian, publikasi, hingga diskusi ilmiah telah dilakukan untuk memperkuat posisi bahasa Indonesia di kancah internasional tersebut. Salah satunya adalah kajian yang dipublikasikan ke dalam jurnal atau prosiding terindeks di Scopus. Melalui tulisan sederhana ini, akan ditunjukkan peta kajian ilmiah tentang BIPA di ranah internasional, khususnya yang terindeks di Scopus. Melalui kajian ini, para pegiat ataupun pemerhati BIPA akan mengetahui dan memiliki gambaran tentang perkembangan kajian BIPA di ranah internasional.

Secara khusus, kajian ini difokuskan untuk melihat tren kajian BIPA dalam empat aspek, yaitu tren kajian BIPA berdasarkan jumlah dokumen dari tahun ke tahun, tren kajian BIPA berdasarkan asal negara penulis, tren kajian BIPA berdasarkan kata kunci, dan tren kajian BIPA berdasarkan hubungan antar penulis.

\section{METODE PENELITIAN}

Penelitian ini menggunakan pendekatan bibliometrik, yaitu suatu kajian analitis yang berbasis pada data bibliografi untuk melihat hubungan suatu topik kajian ilmiah [3]. Penelitian bibliometrik ini dilakukan dengan memanfaatkan data tentang kajian BIPA yang diperoleh dari database Scopus pada aman www.scopus.com. Data dikumpulkan melalui penelusuran dengan menggunakan kata kunci Indonesian for foreign language dengan kategori authors, title, year, affiliations, index keywords, dan document type. Rentang waktu penelusuran data tidak dibatasi mengingat jumlah data yang ditemukan relatif sedikit, yakni hanya sebanyak 201 dokumen. Selanjutnya, data dianalisis dengan menggunakan Microsoft World 2010 untuk mengetahui jumlah kajian BIPA dari tahun ke tahun, jenis dokumen yang ditemukan, asal negara penulis artikel, dan sumbangsih terbanyak penulis artikel. Sementara itu, tren perkembangan kajian di bidang BIPA dianalisis menggunakan aplikasi VOSviewer untuk melihat keterkaitan antardokumen. VosViewer merupakan satu software yang memiliki kemampuan memvisualisasi dan mengeksplorasi hasil kajian bibliometrik [4].

\section{HASIL DAN PEMBAHASAN}

Penelusuran kajian BIPA pada laman scopus dengan kata kunci "Indonesian for foreign language" menghasilkan 201 dokumen. Kata kunci tersebut sengaja dipilih dibandingkan dengan "Indonesian for foreign speakers" yang merupakan terjemahan dari istilah BIPA (bahasa Indonesia bagi penutur asing) dengan mempertimbangkan jumlah dokumen yang ditemukan, yakni hanya 22 dokumen.

Kajian BIPA pada laman scopus menunjukkan tren peningkatan yang cukup signifikan dari tahun ke tahun. Tren peningkatan tersebut dapat dilihat pada Tabel 1 di bawah ini.

Tabel 1. Tren perkembangan kajian BIPA dari tahun ke tahun

\begin{tabular}{rccc}
\hline No & Tahun & Jumlah & Presentase \\
\hline $\mathbf{1}$ & 2019 & 53 & $26,4 \%$ \\
\hline $\mathbf{2}$ & 2018 & 45 & $22,4 \%$ \\
\hline $\mathbf{3}$ & 2017 & 21 & $10,4 \%$ \\
\hline $\mathbf{4}$ & 2016 & 15 & $7,5 \%$ \\
\hline
\end{tabular}




\begin{tabular}{cccc}
\hline $\mathbf{5}$ & 2015 & 14 & $7,0 \%$ \\
\hline $\mathbf{6}$ & 2014 & 7 & $3,5 \%$ \\
\hline $\mathbf{7}$ & 2013 & 4 & $2,0 \%$ \\
$\mathbf{8}$ & 2012 & 3 & $1,5 \%$ \\
\hline $\mathbf{9}$ & 2011 & 9 & $4,5 \%$ \\
\hline $\mathbf{1 0}$ & 2010 & 4 & $2,0 \%$ \\
\hline $\mathbf{1 1}$ & 2009 & 3 & $1,5 \%$ \\
\hline $\mathbf{1 2}$ & 2008 & 1 & $0,5 \%$ \\
\hline $\mathbf{1 3}$ & 2007 & 6 & $3,0 \%$ \\
\hline $\mathbf{1 4}$ & 2003 & 4 & $2,0 \%$ \\
\hline $\mathbf{1 5}$ & 2002 & 2 & $1,0 \%$ \\
\hline $\mathbf{1 6}$ & Sebelum 2000 & 10 & $5,0 \%$ \\
\hline
\end{tabular}

Peningkatan jumlah publikasi tentang BIPA menunjukkan bahwa topik ini dipandang sebagai isu menarik yang perlu dikaji. Tidak hanya itu, BIPA pun tampaknya sudah menjadi topik yang diperhitungkan oleh para chief editor dan publisher. Tabel di bawah ini menunjukkan bahwa penelitian dengan objek kajian BIPA semakin banyak dilakukan. Hasil-hasil penelitian tersebut selanjutnya dipublikasikan dalam berbagai jurnal dan konferensi. Berikut ini adalah datanya.

Tabel 2. Tren publikasi kajian BIPA

\begin{tabular}{llcc}
\hline No & Tipe Dokumen & Jumlah & Presentase \\
\hline $\mathbf{1}$ & Jurnal & 163 & $81,1 \%$ \\
\hline $\mathbf{2}$ & Prosiding Seminar & 29 & $14,4 \%$ \\
\hline $\mathbf{3}$ & Buku & 5 & $2,5 \%$ \\
\hline $\mathbf{4}$ & Book chapter & 4 & $2,0 \%$ \\
\hline & Jumlah & 201 & $100 \%$ \\
\hline
\end{tabular}

Dari 163 dokumen yang ditemukan dalam jurnal, ada empat jurnal yang memiliki jumlah dokumen yang terbanyak, yaitu Indonesian Journal of Applied Linguistics (15 dokumen), Teflin Journal (11 dokumen), Asian EFL Journal (10 dokumen), Pertanika Journal of Social Sciences and Humanities (8 dokumen).

Berdasarkan asal negaranya, penulis asal Indonesia masih mendominasi dengan 136 dokumen. Namun demikian, negara-negara lain seperti Australia, Malaysia, Amerika Serikat, dan Jepang sudah mulai tertarik dengan kajian BIPA ini.

Tabel 3. Tren Kajian BIPA Berdasarkan Asal Negara Penulisnya 


\begin{tabular}{ccc}
\hline No & Asal Negara & Jumlah \\
\hline $\mathbf{1}$ & Indonesia & 136 \\
\hline $\mathbf{2}$ & Australia & 18 \\
\hline $\mathbf{3}$ & Malaysia & 12 \\
\hline $\mathbf{4}$ & Amerika Serikat & 12 \\
\hline $\mathbf{5}$ & Jepang & 8 \\
\hline
\end{tabular}

Berdasarkan kata kunci yang digunakan (co-word), peta perkembangan penelitian BIPA terindeks Scopus membentuk lima kluster seperti tampak pada gambar 1 di bawah. Kluster 1 berwarna merah untuk bidang ilmu language, human, culture, ethnology, multilingualism, male, learning, international cooperation. Kluster 2 berwarna hijau dengan bidang ilmu Indonesian languages, Indonesia, linguistis, speech recognition, information retrieval, local language, computational linguistis. Kluster 3 berwarna biru dengan bidang ilmu learning systems, elearning, Computer aided instruction. Kluster 4 berwarna kuning untuk bidang ilmu students, foreign students, Research methods. Kluster 5 berwarna ungu untuk bidang ilmu teaching, education, information use.

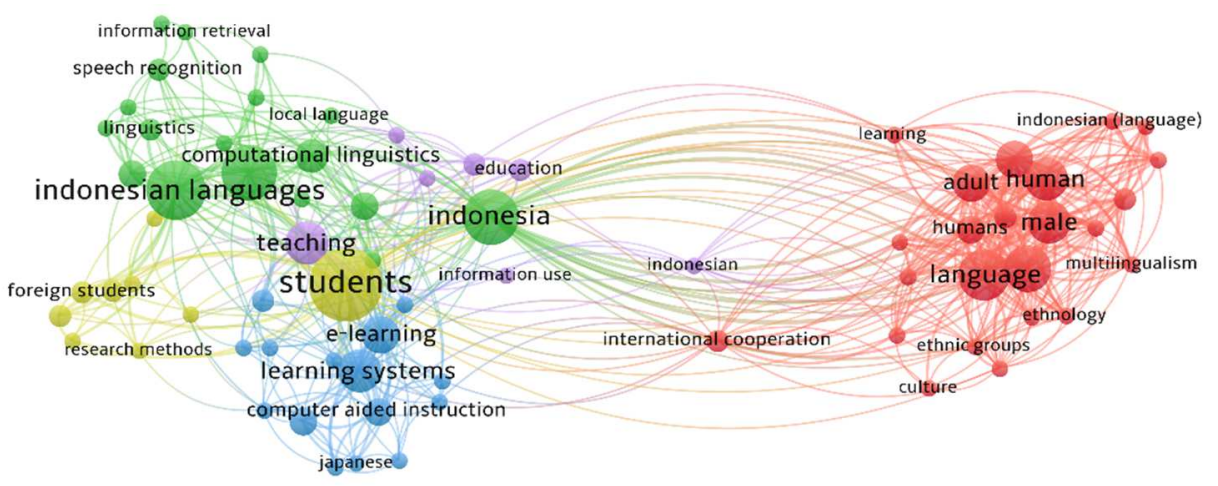

Gambar 1. Peta co-word publikasi bidang BIPA

Gambar 2 di bawah ini menunjukkan bahwa berdasarkan penulis (co-author), penelitian BIPA terindeks Scopus membentuk lima kluster. Kluster 1 berwarna merah terdiri atas Mukminin A., Muazza M., Haryanto E., Kamil D., Abdurrahman K., Sulistiyo U., Wiryotinoyo M., Wulan R.. Kluster 2 berwarna biru terdiri atas Habibi A., Rohayati T., Putra H.A., Aina M., Erlina D., Astrid A.. Kluster 3 berwarna kuning terdiri atas Marzulina L., Yaakob M. F. M., Desvitasari D., Ropawandi D.. Kluster 4 berwarna hijau terdiri atas Harto K., Sofwan M., Najwan J., Sirozi M., Haswindy S.. Kluster 5 berwarna ungu terdiri atas Muhaimin, Taridi M., Ikhsan, Saudagar F. 


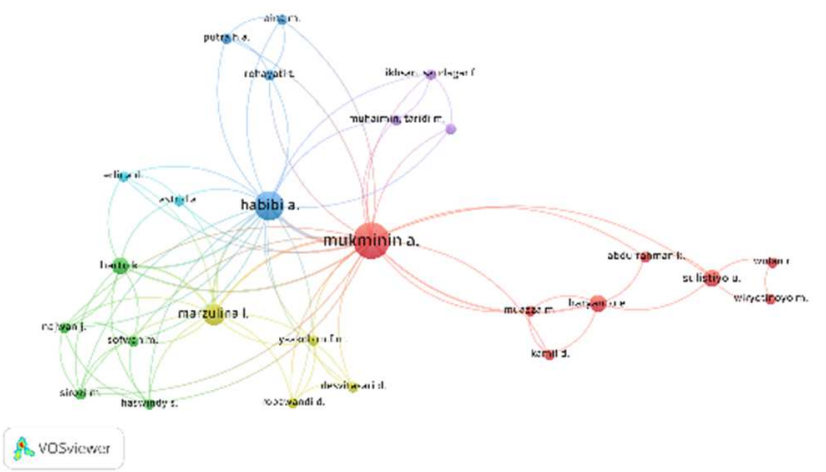

Gambar 2. Peta co-author publikasi bidang BIPA

Sementara itu, ada beberapa penulis yang memiliki sumbangsih besar bagi kajian BIPA di Scopus, yakni sebagaimana bisa dilihat dari Tabel 4 di bawah ini.

Tabel 4. Sumbangsih Penulis terhadap Kajian BIPA

\begin{tabular}{ccc}
\hline No & Nama & Jumlah \\
\hline $\mathbf{1}$ & Mukminin, A. & 7 \\
\hline $\mathbf{2}$ & Saddhono, K. & 6 \\
\hline $\mathbf{3}$ & Habibi, A. & 5 \\
\hline $\mathbf{4}$ & Oktriono, K. & 4 \\
\hline $\mathbf{5}$ & Hassall, T.; Marzulina, L.; Ningsih, \\
& R.Y.; Salikin, H. & 3 \\
\hline
\end{tabular}

Kajian tentang Indonesian for foreign language berdasarkan penelusuran nama penulis menghasilkan data sebagaimana terlihat pada Tabel 4 di atas. Akan tetapi, ketika ditelusuri lebih lanjut, para penulis di atas memiliki dua latar belakang keilmuan, yaitu bidang pendidikan bahasa Inggris dan bidang pendidikan bahasa Indonesia. Penulis yang berlatar belakang bahasa Inggris adalah Mukmin, Habibi, dan Hassall, Marzulina, Ningsih, \& Salikin. Sementara itu, Saddhono dan Oktriono memiliki latar belakang keilmuan di bidang bahasa Indonesia dan secara fokus banyak meneliti tentang BIPA. Dari data ini, dapat disimpulkan bahwa kedua penulis yang disebutkan belakang ini adalah pakar BIPA yang paling banyak memublikasikan tulisannya di Scopus. Saddhono banyak menyoroti persoalan BIPA dari sudut pandang budaya dan pemanfaatan teknologi dalam pembelajarannya. Sementara itu, Oktriono lebih menekankan pada aspek penilaian kompetensi mahasiswa BIPA.

Dengan mendasarkan pada hasil-hasil di atas, kajian tentang BIPA memiliki posisi strategis untuk diteliti lebih lanjut. Beberapa topik kajian BIPA yang sudah ditemukan antara lain pengintegrasian materi ajar BIPA dengan budaya nasional Indonesia [5] maupun budaya lokal seperti misalnya budaya Jawa [6]. Pemanfaatan teknologi informasi seperti media sosial (facebook) [8], mobile android [7], atau pembelajaran berbasis multimedia [9] juga menjadi topik kajian BIPA sebagai upaya peningkatan kualitas pengelolaan dan pembelajaran BIPA. Selain pengembangan materi ajar dan pemanfaatan media inovatif, kajian tentang evaluasi terhadap pembelajaran BIPA juga banyak ditemukan, di antaranya pengembangan UKBI berbasis web [12], kebutuhan pengembangan tes kompetensi menulis [13], dan strategi peningkatan kemampuan menyimak [14]. Selain ketiga topik di atas, tentu masih banyak 
peluang topik-topik lain terkait dengan BIPA yang memungkinkan untuk digarap dan dipublikasikan. Artikel yang sederhana ini pemacu tumbuh berkembangnya kajian BIPA di ranah internasional.

\section{SIMPULAN}

Berdasarkan hasil analisis di atas, dapat diambil simpulan bahwa tren kajian BIPA pada laman Scopus mengalami peningkatan dari tahun ke tahun. Peningkatan tersebut secara signifikan terlihat pada tahun 2018 dan 2019, yakni sebanyak 45 dokumen (22,4\%) pada tahun 2018 dan 53 dokumen $(26,4 \%)$ pada tahun 2019. Dokumen publikasi tersebut didominasi oleh dokumen berbentuk artikel jurnal, yakni sebanyak 163 dokumen (81,1\%). Sementara itu, peringkat jurnal yang memublikasikan kajian BIPA adalah Indonesian Journal of Applied Linguistics (15 dokumen), Teflin Journal (11 dokumen), Asian EFL Journal (10 dokumen), Pertanika Journal of Social Sciences and Humanities ( 8 dokumen). Kajian BIPA masih didominasi oleh penulis-penulis dari Indonesia, namun, penulis dari negara-negara lain, seperti Australia, Malaysia, Amerika Serikat, dan Jepang juga sudah banyak yang tertarik dengan bidang ini. Tren perkembangan kajian BIPA berdasarkan co-word dan co-author sama-sama mengelompok menjadi lima kluster. Sementara itu, penulis yang memberikan sumbangsih besar bagi perkembangan kajian BIPA antara lain Mukminin, A. (7 dokumen), Saddhono, K. (6 dokumen), Habibi, A. (5 dokumen), Oktriono, K. (4 dokumen), serta Hassall, T., Marzulina, L., Ningsih, R.Y., dan Salihin, H. (3 dokumen). Dengan melihat perkembangan yang sudah disampaikan dalam penelitian ini, diharapkan para pemerhati dan pegiat BIPA bisa memanfaatkannya untuk lebih mengeksplorasi dan memperkaya topik-topik kajian BIPA. Dengan begitu, eksistensi BIPA di ranah internasional dapat terus dijaga dan ditingkatkan.

\section{REFERENCES}

[1] N. K. Ranawati, "56 Negara Pelajari Bahasa Indonesia, Berpotensi Jadi Bahasa Internasional," Ayobandung.com, 27-Jun-2019.

[2] Hertiki, "Pengajaran dan Pembelajaran BIPA di Perguruan Tinggi Polandia," $J$. Pendidik. Bhs. dan Sastra Indones., vol. 6, no. 2, pp. 1-5, 2017.

[3] Tupan, R. N. Rahayu, R. Rachmawati, and E. S. R. Rahayu, "Analisis Bibliometrik Perkembangan Penelitian Bidang Ilmu Instrumentasi," BACA J. Dokumentasi dan Inf., vol. 39, no. 2, pp. 135-149, 2018.

[4] L. Leydesdorff and I. Rafols, "Interactive overlays: A new method for generating global journal maps from Web-of-Science data,” J. Informetr., vol. 6, pp. 318-332, 2012.

[5] K. Saddhono, "Integrating culture in Indonesian language learning for foreign speakers at Indonesian universities," J. Lang. Lit., vol. 6, no. 2, pp. 273-276, 2015.

[6] K. Saddhono, "Cultural and social change of foreign students in Indonesia: The influence of Javanese Culture in Teaching Indonesian to Speakers of Other Languages (TISOL)," in IOP Conference Series: Earth and Environmental Science, 2018.

[7] R. Rahim, K. Saddhono, and S. Hastuti, "Prototype Mobile Based Android Application for TISOL Learning," J. Adv. Res. Dyn. Control Syst., vol. 11, no. 7, pp. 362-365, 2019.

[8] K. Saddhono, A. Hasibuan, and M. I. Bakhtiar, "Facebook as A Learning Media in TISOL (Teaching Indonesian to Speakers of Other Languages) Learning to Support the Independency of Foreign Students in Indonesia," in Journal of Physics: Conference Series, 2019.

[9] K. Saddhono, Suhartatik, Bagiya, Widodo, and H. Wahyono, "Learning vocabularies 
using multimedia-based Teaching Indonesian to Speakers of Other Languages (TISOL)," in 1st International Conference Computer Science and Engineering, 2019.

[10] R. Y. Ningsih, K. Oktriono, C. K. Wiharja, and E. Ernawati, "Forms of language errors in speaking practices of foreign students through online UKBIPA application," in $A C M$ International Conference Proceeding Series, 2018, pp. 59-62.

[11] K. Oktriono and Wishnoebroto, "Need analysis for CLIL synchronization in BIPA learning," Adv. Sci. Lett., vol. 23, no. 2, pp. 941-943, 2017.

[12] K. Oktriono, "UKBI: Experimental development of web-based Indonesian language proficiency test for foreign speakers," in Journal of Physics: Conference Series, 2019.

[13] L. E. Rahmawati, S. Suwandi, K. Saddhono, and B. Setiawan, "Need analysis on the development of writing competency test for foreign university students," Humanit. Soc. Sci. Rev., 2019.

[14] M. Sudaryanto, D. Mardapi, and S. Hadi, "How foreign speakers implement their strategies to listen indonesian language?," J. Adv. Res. Dyn. Control Syst., 2019. 